\title{
Erratum to: The effect of joint size on the creep properties of microscale lead-free solder joints at elevated temperatures
}

Limeng Yin $\cdot$ Song Wei $\cdot$ Zhangliang Xu •

Yanfei Geng • Diganta Das $\cdot$ Michael Pecht

Published online: 31 July 2013

(C) Springer Science+Business Media New York 2013

Erratum to: J Mater Sci: Mater Electron

(2013) 24:1369-1374

DOI 10.1007/s10854-012-0936-x

Unfortunately, the 5th and 6th coauthors were not listed in the author group of the original publication. The revised author group and their affiliations are listed correctly in this erratum.

The online version of the original article can be found under doi:10.1007/s10854-012-0936-x.

L. Yin $(\bowtie) \cdot S$. Wei $\cdot$ Z. Xu $\cdot$ Y. Geng

School of Metallurgy and Materials Engineering,

Chongqing University of Science and Technology,

Chongqing 401331, China

e-mail: yinlimeng@cqust.edu.cn

D. Das - M. Pecht

Center for Advanced Life Cycle Engineering, University

of Maryland, College Park, MD 20472, USA 